
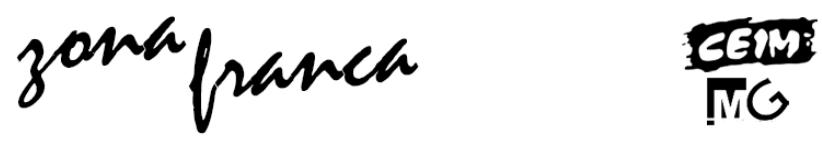

CENTRO DE ESTUDIOS

INTERDISCIPLINARIOS SOBRE MUJERES

MAESTRÍA "PODER Y SOCIEDAD

DESDE LA PROBLEMATICA DE GÉNERO"

\title{
Representaciones de las mujeres en la cobertura informativa de las negociaciones de paz en Colombia. Las mujeres como víctimas protagónicas en los periódicos EI Colombiano y EI Tiempo (2013-2016)
}

\section{Resumen}

Sandra Patricia Valoyes Villa

Este artículo aborda las representaciones sobre las mujeres afectadas por el conflicto armado colombiano, que se difundieron en medios impresos durante la cobertura de los acuerdos de paz desarrollados entre 2013 y 2016. De modo general, el análisis refleja una precaria inclusión de temas que involucran particularmente a las mujeres en el contexto del conflicto y la paz, una baja presencia de fuentes y menciones a mujeres en los relatos informativos, así como su ubicación en las posiciones menos relevantes de la estructura jerarquizada de los textos periodísticos. De modo más específico, se detecta que las mujeres afectadas por el conflicto armado se ubican en niveles co-protagónicos y son referenciadas como testimoniantes de la guerra en permanentemente asociación con sus relaciones familiares. En conjunto, estos hallazgos presentan un estado de la situación de las mujeres en el marco de los acuerdos de paz entre el gobierno colombiano y la entonces guerrilla de las Farc-Ep, que exhibe las ideas construidas y difundidas sobre la participación de las mujeres en distintos escenarios de la sociedad.

Palabras clave: Representaciones de las mujeres- medios de comunicación de masas- procesos de paz- análisis de contenido y discurso- mujeres víctimas del conflicto armado.

\section{Representations of women affected by the armed conflict, in the coverage of the newspapers EI Colombiano and EI Tiempo during the peace agreements in Colombia (2013-2016)}

\section{Abstract}

\footnotetext{
"Universidad de Antioquia, Red Colombiana de Periodistas con Visión de Género Contacto: sandra.valoyes.villa@gmail.com
}

Valoyes Villa, Sandra Patricia. "Representaciones de las mujeres en la cobertura informativa de las negociaciones de paz en Colombia. Las mujeres como víctimas protagónicas en los periódicos $\mathrm{El}$ Colombiano y El Tiempo (2013-2016)" en Zona Franca. Revista del Centro de estudios Interdisciplinario sobre las Mujeres, y de la Maestría poder y sociedad desde la problemática de Género, N²6, 2018 pp.178-204. ISSN, 2545-6504

Recibido: 1 de junio, 2018; Aceptado: 26 de octubre 2018

Revista Zona Franca- Centro de estudios interdisciplinario sobre las mujeres (CEIM)- Maestría poder y sociedad desde la problemática de género (MG), Rosario, Argentina. ISSN, 2545-6504 http://zonafranca.unr.edu.ar/index.php/ZonaFranca| Numero 26 (2018). 
This paper presents the portrayals of women affected by the armed colombian conflict, in print media coverage during the peace agreements developed in Colombia between 2013 and 2016. In general, the analysis reflects a precarious inclusion of themes that involve women in the context of conflict and peace, a low presence of feminine sources and mentions in informative stories, as well as their location in the least relevant positions in the hierarchical structure of the informative pieces. More specifically, the analysis detects that women who were victims of the armed conflict, are located in co-leading levels and as witnesses of the war and associated with their family relationships. Taken together, these findings present a state of the situation of women in the context of peace agreements between the Colombian government and the then Farc-Ep guerrilla, as they reflect the ideas built and disseminated about the participation of women in different scenarios of society.

Keywords: Women's portrayals- mass media- peace agreements- content analysis and discourse analysis- women's victims of the armed conflict.

\section{Introducción}

Colombia es un país en el cual se han desarrollado conflictos políticos y sociales que, desde el siglo XIX, han derivado en conflictos armados con diversos actores, y han afectado a la población con despojo del territorio y bienes muebles e inmuebles, amenazas, delitos contra la libertad y la integridad sexual, desaparición forzada, desplazamiento, secuestro, tortura, vinculación de niños, niñas y adolescentes al conflicto, homicidio, actos terroristas y minas antipersonal. El Registro Único de Víctimas (RUV) cuantifica a 8.332.081 víctimas en Colombia, de las cuales 4.135.870 son mujeres (RUV 2018) $)^{1}$. El RUV establece que el daño más notorio en contra de las mujeres por ocasión del conflicto está enmarcado en la violencia sexual, reportándose 22.439 casos en contra de las mujeres y 1.875

\footnotetext{
${ }^{1}$ La Red Nacional de Información para la Atención y Reparación a las Víctimas (RNI), recopila en el RUV información relacionada con las víctimas desde 1985 a 2018. También considera algunos registros previos al año 1985. Los datos están actualizados al 1 de mayo de 2018 y se encuentra disponible en https://rni.unidadvictimas.gov.co/RUV

Revista Zona Franca- Centro de estudios interdisciplinario sobre las mujeres (CEIM)- Maestría poder y sociedad desde la problemática de género (MG), Rosario, Argentina. ISSN, 2545-6504 http://zonafranca.unr.edu.ar/index.php/ZonaFranca| Numero 26 (2018). 
en contra de los hombres. A lo anterior se agrega que, en la encuesta de prevalencia de violencia sexual en el marco del conflicto armado desarrollada entre 2010 y 2015, en 142 municipios con presencia de actores armados (fuerza pública, guerrilla y paramilitares o BACRIM) se encuentra que:

875.437 mujeres fueron víctimas directas de algún tipo de violencia sexual. Este dato representa que anualmente, en promedio, 145.906 mujeres fueron víctimas directas de algún tipo de violencia sexual, 12.158 lo fueron cada mes, 400 lo fueron cada día y 16, cada hora. (Sánchez, Carrillo, Babativa, Rengifo y Silva 2017:5).

La preocupación frente a este tipo de impactos sobre la vida y cuerpo de las mujeres, y los producidos en la sociedad en general, influyen en su decisión de apostar a la paz desde el movimiento social y las organizaciones de la sociedad civil. Por ello, en los años noventa se crearon y consolidaron redes e iniciativas de mujeres por la paz para plantear alternativas para la negociación del conflicto armado, reclamar los derechos de las mujeres, develar de manera diferenciada sus afectaciones en el contexto de la guerra, y participar en escenarios políticos para la negociación del conflicto y el posconflicto en el país (Luna y Villarreal 2011; Tamayo 2013; Sánchez y Rodríguez, 2015).

En el año 2012, el gobierno de Colombia inició de manera oficial -y después de fallidos intentos de negociación en gobiernos anteriores- conversaciones con la guerrilla de las Farc-Ep para darle fin al conflicto armado. Para el diálogo se instaló una Mesa de Conversaciones en La Habana, Cuba, donde se propusieron los puntos de negociación que quedaron consignados en el "Acuerdo General para la terminación del conflicto y la construcción de una paz estable y duradera" (Alto 
Comisionado para la paz 2012). En 2016 se finaliza el proceso con un acuerdo avalado por el Congreso de la República.

En el mundo y sobre todo después de la IV Conferencia Mundial sobre la Mujer (ONU 1995), cada vez más se viene ratificando la importancia de la presencia de las mujeres en las negociaciones de paz, a razón del impacto diferencial que ellas reciben en el desarrollo de los conflictos armados (Mesa 2010). De este certamen se derivan acciones como la Resolución 1325 aprobada por el Consejo de Seguridad de las Naciones Unidas que a partir del año 2000 reconoce el impacto de la guerra en la vida de las mujeres e insta a los gobiernos para que en eventuales negociaciones de paz participen las mujeres y se incluya la perspectiva de género.

La participación de las mujeres en el proceso de paz entre el gobierno colombiano y la guerrilla de las Farc fue reconocida en 2013, un año después de iniciado el mismo; en 2014 se instaló la Subcomisión de Género en la Mesa de Conversaciones y en 2016 se presentaron públicamente los resultados de esta nueva modalidad de participación de las mujeres en las negociaciones de paz.

En este artículo se presentan algunos resultados derivados de la investigación "Representaciones de las mujeres en el cobertura informativa de los periódicos El Colombiano y El Tiempo durante las negociaciones de paz en Colombia entre el gobierno y las Farc (2013-2016)”². La investigación se fijó los objetivos de analizar las representaciones de las mujeres partiendo de la

\footnotetext{
${ }^{2}$ El estudio se realizó en la Maestría en Comunicaciones, línea de Análisis de contenido, producción y recepción de medios, en la modalidad de Investigación. Facultad de Comunicaciones de la Universidad de Antioquia, Colombia.
}

Revista Zona Franca- Centro de estudios interdisciplinario sobre las mujeres (CEIM)- Maestría poder y sociedad desde la problemática de género (MG), Rosario, Argentina. ISSN, 2545-6504 http://zonafranca.unr.edu.ar/index.php/ZonaFranca| Numero 26 (2018). 
identificación y categorización de los tipos y niveles de su presencia en los periódicos elegidos, con el propósito de establecer también el lugar que ocupan ellas y los temas de género en la agenda informativa de estos medios.

Primero se presentarán, de modo general, las formas en las que El Colombiano y El Tiempo reflejaron a las mujeres en las piezas periodísticas. Después, de modo más específico, el análisis se centrará en aquellas representaciones en las que los dos medios presentaron como protagonistas a las mujeres afectadas por el conflicto armado. Estas representaciones se privilegian en el texto debido a que surgen en la información en lugares relevantes por su testimonio de la guerra en relación a la negociación de la paz.

Las investigaciones desarrolladas en Colombia sobre medios de comunicación, conflicto armado y paz, según Tamayo y Bonilla (2014) se han enfocado en tres tendencias, la primera, aborda el ejercicio periodístico, sus riesgos y garantías; la segunda, las agendas de los medios y su relación con las fuentes de información, los lenguajes y los públicos; y, la tercera, introduce un escenario de "(pos)conflicto, víctimas y memoria" (p.18). Sin embargo, no se puede establecer en ninguna de las tendencias, una preocupación que conjugue temas asociados a la cobertura mediática con las representaciones construidas sobre las mujeres en contextos de paz, posconflicto o posacuerdos, lo que ha imposibilitado reconocer, entre otros aspectos, la participación de las mujeres como combatientes, como movimiento de mujeres y feministas pacifistas, entre otras. (Londoño y Nieto 2006; Castrillón 2015). 


\section{Enfoque Teórico}

Este análisis parte del concepto de representaciones y planteamientos del paradigma crítico de la comunicación mediática, en concordancia con los postulados provenientes del pensamiento feminista y los estudios de género. Entendiendo que los textos son, como lo expresa Fairclough (1995) "espacios sociales donde dos procesos sociales fundamentales se producen simultáneamente: conocimiento y representación del mundo, e interacción social" (p.11), se reconoce el paradigma crítico de la comunicación desde su planteamiento de la "interlocución y permanente construcción de sentidos a través de los cuales sea posible establecer una comprensión de las relaciones sociales" (Navarro 2008:330).

Las representaciones sociales según Jodelet (1986) -quien retoma los desarrollos del gestor de la teoría, Serge Moscovici- son una forma de conocimiento social que se constituye en "modalidades de pensamiento práctico orientadas hacia la comunicación, la comprensión y el dominio del entorno social, material e ideal" (pp.474-475). Este enunciado consigna la relación general existente entre las representaciones y la comunicación y modalidades más específicas como la noticia.

Alcina (1993) define la noticia como "una representación social de la realidad cotidiana producida institucionalmente que se manifiesta en la construcción de un mundo posible" (p.185) y donde se conjugan "mundo real" o de los acontecimientos y "mundo de referencia" o de encuadre de los hechos, para coconstruir el relato del "mundo posible" (pp.188-190). La narración de ese "mundo 
posible" se elabora a partir de una imagen que, según Horta (2013), es "la autorreferencia social del presente, entendida como la conciencia colectiva capaz de generar conocimiento de los hechos presentes y pertenencia social del individuo en su sociedad" (p.97).

Este análisis se sirve a su vez de herramientas teóricas y conceptuales propuestas desde el pensamiento feminista, debido a que han posibilitado la comprensión sobre el modelo androcéntrico que las sociedades occidentalizadas tienden a compartir y legitimar, proponiendo al hombre como parámetro y centro de todas las cosas (Sau, 2000). Los planteamientos feministas se han ocupado de develar las lógicas sociales y culturales en la cuales se ha desenvuelto la participación de las mujeres en la sociedad y en su historia; y, como campo de construcción de conocimiento de las dinámicas de la subordinación de las mujeres y de exclusión de lo femenino, han posibilitado condiciones para el reconocimiento de derechos sociales, políticos, económicos y culturales para las mujeres. Tal y como lo afirman Burkle y Reigada (2006), este pensamiento ha ejercido "la crítica de la cultura y la sociedad" (pp.12-13).

La producción periodística y los discursos mediáticos no son ajenos a las dinámicas dicotómicas y de construcción tradicional de los géneros en la sociedad, pues los acontecimientos, aunque externos al sujeto, como señala Alcina (1993) "no tienen sentido al margen de los sujetos" (p.81) y sus relatos son "el lugar donde la indagación del sentido se muestra más fértil para observar las dinámicas 
de construcción de lo social y de las mujeres por parte de los medios de comunicación" (Sánchez 2007:77).

En la narración para el caso de la prensa escrita, "el diario, como producto final, presenta al lector una propuesta de ordenación, estructuración y jerarquización de la realidad que quiere representar" (Montero 1997:165). Este aspecto se considera central en el análisis precisamente porque es a partir de este proceso de ordenación de la información donde se define qué es noticia y quiénes son sus protagonistas.

\section{Metodología}

El estudio del que se desprende este análisis se realizó bajo una metodología mixta en la que se combina la técnica cuantitativa, con un Análisis de Contenido (AC), y la cualitativa, con un Análisis de Discurso (AD).

Se definieron los periódicos El Colombiano y El Tiempo, debido a que cuentan con un mayor número de lectores a nivel regional y nacional respectivamente. Adicionalmente, ambos medios tienen una historia fundacional de más de 100 años y su vida está enmarcada por su filiación con los partidos políticos tradicionales colombianos Conservador y Liberal, lo que los ubica como periódicos de carácter hegemónico que dadas sus características y lógicas de producción, se construyen en una fuente para la exploración de las representaciones que circulan sobre las mujeres, que pueden ir desde las más dominantes hasta las que se encuentran en disputa, como "formas de pensamiento social" que remiten a una manifestación de las características de una sociedad determinada. 
El Universo del análisis está compuesto por 836 piezas periodísticas que los diarios seleccionados publicaron sobre el proceso de paz, en nueve periodos definidos a partir de la firma de cada uno de los acuerdos, y otras fechas consideradas relevantes como la presentación del enfoque de género y el plebiscito.

\section{Tabla 1}

Fechas de firmas por acuerdo de paz y periodos de análisis

\begin{tabular}{|c|c|c|}
\hline Nombre de Acuerdo & Fecha firma de Acuerdo & Periodos de análisis \\
\hline $\begin{array}{llr}\text { "Hacia un } & \text { nuevo } & \text { campo } \\
\text { colombiano: } & \text { Reforma } & \text { rural } \\
\text { integral" } & & \end{array}$ & 26 de mayo de 2013 & 22 al 30 de mayo de 2013 \\
\hline "Participación política" & 6 de noviembre de 2013 & 2 al 10 de noviembre de 2013 \\
\hline $\begin{array}{l}\text { "Solución al problema de las } \\
\text { drogas ilícitas" }\end{array}$ & 16 de mayo de 2014 & 12 al 20 de mayo de 2014 \\
\hline "Víctimas" & 15 de diciembre de 2015 & $\begin{array}{l}11 \text { al } 19 \text { de diciembre de } \\
2015\end{array}$ \\
\hline "Cese del fuergo" & 23 de junio de 2016 & 19 al 27 de junio de 2016 \\
\hline Inclusión del enfoque de género & 24 de Julio de 2016 & 20 al 28 de julio de 2016 \\
\hline Acuerdo final & 27 de septiembre de 2016 & $\begin{array}{l}22 \text { al } 30 \text { de septiembre de } \\
2016\end{array}$ \\
\hline Plebiscito & 2 de octubre de 2016 & 1 al 6 de octubre de 2016 \\
\hline Acuerdo final ajustado & 24 de noviembre de 2016 & $\begin{array}{l}20 \text { al } 28 \text { de noviembre de } \\
2016\end{array}$ \\
\hline
\end{tabular}

Para el AC se estableció una muestra conformada por 306 piezas periodísticas (36\% del Universo), seleccionadas por la presencia de al menos uno de los siguientes criterios: 1 . Temas específicos sobre las mujeres y la paz; 2. 
Mujeres como fuentes de información; y 3. Menciones específicas a mujeres. A estas piezas se les aplicó una ficha de registro de datos como instrumento.

\section{Gráfico 1}

Piezas periodísticas según periodos de análisis y medio de comunicación

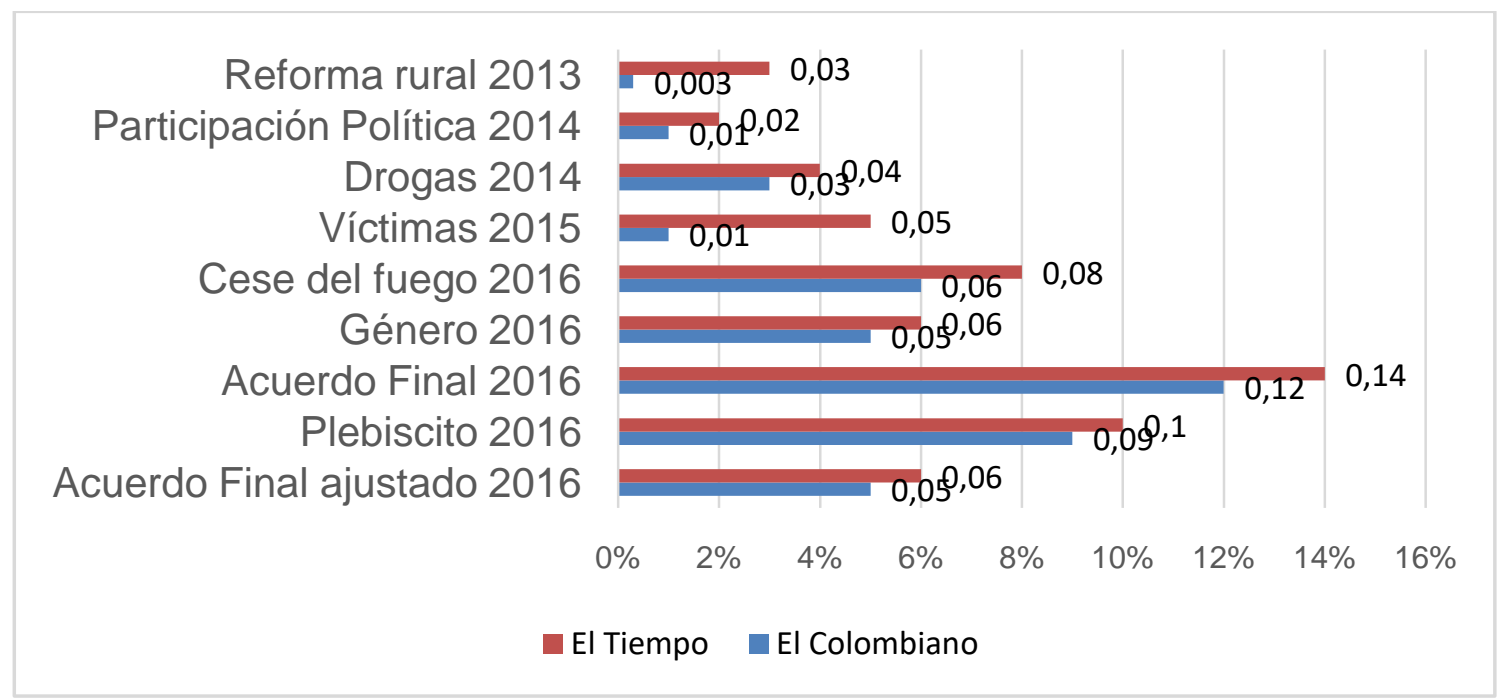

El AD se desarrolló con una submuestra a la cual se le aplicó un análisis léxico computacional donde se revisaron frecuencias y concordancias de palabras claves en contexto. La submuestra se compuso de 41 piezas periodísticas (13\% de la muestra), en las que estuvieron presentes los siguientes elementos: 1. Desarrollo de temas específicos sobre las mujeres y la paz; y 2. Inclusión de mujeres como fuentes principales o protagónicas.

\section{Las mujeres en la cobertura de los acuerdos de paz: análisis de contenido}

A partir de los resultados de la muestra se puede apreciar que los temas que se refirieron exclusivamente a las mujeres y la paz alcanzaron sólo el 3.22\% de la información difundida, que obtuvo -en número de piezas- la misma proporción en los dos diarios analizados. Los periodos correspondientes a la presentación del 
enfoque de género en los acuerdos de paz y el acuerdo final ajustado fueron, paradójicamente, los que menor número de piezas periodísticas reportaron en 2016, año que cubre el $86 \%$ de la muestra. La información relacionada con la inclusión del enfoque de género en los acuerdos estuvo influenciada en gran medida por las campañas del plebiscito.

\section{Mujeres en la estructura del texto periodístico}

La estructura de la noticia como pirámide invertida representa la relevancia de datos y personajes del acontecimiento, que se distribuyen en el texto de mayor a menor según su grado de importancia. La única categoría que puede ser totalizada debido a que está presente en todas las piezas periodísticas es el titular, que, definido por Van Dijk (1990), constituye "la esencia, el resultado o la información más importante de la información periodística” (p.253). Allí se pudo establecer que en este espacio destacado se nombraron a las mujeres en un $13 \%$.

Con lo anterior se constata que las mujeres en la construcción jerarquizada de la noticia no soportan lugares protagónicos cuando se trata de temas asociados a la paz, y se puede establecer una tendencia que demuestra que las mujeres tienen mayor presencia en los párrafos intermedios y finales (65\% y $49 \%$ ), lo que significa que, aunque mencionadas o como fuentes directas, no se constituyen como los centros de la información publicada.

\section{Mujeres como fuentes de información}

En la muestra se detectaron 376 mujeres como fuentes de información, es decir, un $27 \%$ del total de las fuentes incluidas en ambos medios (mujeres y 
hombres). Como se puede observar, las mujeres como fuente directa de información obtuvieron un nivel bajo de presencia en ambos medios, en comparación con los varones, aspecto que permite deducir que tanto los tópicos relacionados con las mujeres y la paz, como su inclusión como fuentes, no se consideró relevante en la elaboración de la información que sobre los acuerdos de paz se publicó en los medios y periodos analizados.

El $67 \%$ de las mujeres que actuaron como fuentes de información, se describieron vinculadas con alguna organización o institución. Aquellas con una vinculación al gobierno o al Estado estuvieron asociadas en un 52\%.

Aunque algunas fuentes portaron varias asociaciones institucionales, la relación de estas a partidos políticos fue del 30\%. A esta categoría le siguieron en número las que se vincularon con organizaciones no gubernamentales, que alcanzaron un $13 \%$, y con la academia que obtuvo el mismo porcentaje. $\mathrm{Y}$, en un lugar más bajo, se ubicaron guerrilleras de las Farc-Ep con un 5\%. La asociación a sindicatos o iglesias no arrojó ningún registro.

Al indagar por otras características, se encuentra que el $10 \%$ de las fuentes se definieron con su edad, en su mayoría en el rango de jóvenes/adultas. En la categoría etnia se encontró una asociación del 1.6\%. Sólo se reporta a una mujer descrita con un tipo de discapacidad y ninguna fuente es referenciada con una vinculación a categorías LBTI. Las mujeres consultadas asociadas a la maternidad y a su estado civil obtuvieron una presencia, para el primer caso de un $8 \%$, y para el segundo de un $5 \%$. Sobre el estado civil, fueron equitativas sus identificaciones como casadas o viudas. La asociación a relaciones íntimas o familiares que 
identificaron a las mujeres madres y a las viudas demuestra una correlación entre lazos familiares y el protagonismo que ambas figuras representan en los medios de comunicación.

\section{Las mujeres y su protagonismo en las negociaciones de paz: análisis de}

\section{discurso}

El periódico El Tiempo aportó un mayor número de piezas en la muestra (58\%) y en la submuestra (71\%), lo que indica que este medio publicó más contenidos en los que tanto los temas sobre mujeres en intersección con la paz, como las mujeres como fuentes de información, se ubicaron en un nivel protagónico más alto en comparación con El Colombiano.

La presentación de la inclusión del enfoque de género en los acuerdos es significativa en la submuestra, consecuencia del primer criterio de selección de la misma. Estos asuntos, por afectar a las mujeres de modo más directo, evidencian su ubicación en lugares más destacados y, en alguna medida, aseguran el incremento de su presencia en el periodo posterior con más número de publicaciones sobre el proceso de paz, que fue el momento en el que se firmaron los acuerdos de paz en la ciudad de Cartagena de Indias en el año 2016.

\section{Colectivo Mujeres, violencia y paz}

En la submuestra, el colectivo mujeres se despersonaliza y se visualiza a través de líneas temáticas. Aunque la aparición de un tema no limita la presencia de otro, pues en ocasiones los tópicos se entremezclan o se complementan, las mujeres como colectivo obtuvieron una asociación con asuntos que, además o a partir de la paz, aludieron principalmente a la participación política (10\%), a su promoción en la sociedad (13\%), a los derechos humanos (15\%), y a las violencias o afectaciones ejercidas contra ellas en el ámbito del conflicto armado (22\%).

Revista Zona Franca- Centro de estudios interdisciplinario sobre las mujeres (CEIM)- Maestría poder y sociedad desde la problemática de género (MG), Rosario, Argentina. ISSN, 2545-6504 http://zonafranca.unr.edu.ar/index.php/ZonaFranca| Numero 26 (2018). 
Particularmente cuando se hace alusión a las mujeres en concordancia con la paz (10\%), se les propone en exigencia de sus derechos vulnerados $\mathrm{y}$, al tiempo que se les presenta como sujetos pasivos que deben ser intervenidos, se les eleva como agentes de paz con destacados como:

- "La antorcha de la reconciliación reposará en las mujeres de Colombia” o encabezados como:

- "Juana, la tejedora del perdón"4.

Estos elementos denotan algunas de las representaciones que comúnmente se asocian a las mujeres en marcos de guerra o paz y están directamente ligadas a estereotipos difundidos de los roles tradicionales de género, reproduciendo la idea esencialista según la cual las mujeres son pacíficas por naturaleza, "símbolo de paz, de todo aquello que hay que proteger y por lo que hay que luchar", en comparación con la construcción "que hace de la violencia un atributo de los hombres" (Magallón 2012:20), dicotomía que presenta una imagen que refuerza a "los hombres como agentes activos de la violencia y a las mujeres como sus víctimas pasivas" (Villellas 2010:25). Para Magallón (2012) "la unión esencialista de las mujeres con la paz no se corresponde con la pluralidad de comportamientos de las mujeres de carne y hueso, ni tan siquiera con las que se oponen a la violencia" (p.20).

Sin embargo, la línea temática con mayor presencia en la información, con mujeres protagonistas, es su asociación como víctimas de la violencia en el marco del conflicto armado colombiano, alcanzando un $22 \%$ en el registro de concordancias en relación directa con las palabras Mujer y Mujeres.

\footnotetext{
${ }^{3}$ Rendón, O. (25 de julio de 2016). El enfoque de género está listo en los diálogos con las Farc. El Colombiano, p.7

${ }^{4}$ Palomino, S. (25 de mayo de 2013). Liderazgo y tenacidad de cuatro mujeres afro. El Tiempo, p. 30
}

Revista Zona Franca- Centro de estudios interdisciplinario sobre las mujeres (CEIM)- Maestría poder y sociedad desde la problemática de género (MG), Rosario, Argentina. ISSN, 2545-6504 http://zonafranca.unr.edu.ar/index.php/ZonaFranca| Numero 26 (2018). 
De manera que el ser víctimas se incluye no sólo como tópico derivado del tema violencia, sino que se constituye como otra manera de presentar, retomando a Brah (2004), "matrices de significados" (p.132) relativas al ser mujeres en el contexto del conflicto armado y la construcción de paz.Si retomamos el concepto de representaciones como modalidad de pensamiento práctico encaminada a la comunicación, comprensión y dominio del entorno social, material e ideal (Jodelet 1986), las mujeres víctimas pueden considerarse como una forma de representación debido en gran medida a su reiterada presencia en la información analizada. A continuación, se presentarán las maneras en las que esta representación se posicionan en niveles protagónicos en los textos informativos revisados.

\section{Mujeres como víctimas del conflicto armado}

En la Ley 1448 o Ley de Víctimas y Restitución de Tierras promulgada en Colombia en el año 2011, la noción de víctimas del conflicto armado está expuesta como todas "aquellas personas que individual o colectivamente hayan sufrido un daño (...) como consecuencia de infracciones al Derecho Internacional Humanitario o de violaciones graves y manifiestas a las normas internacionales de Derechos Humanos, ocurridas con ocasión del conflicto armado interno" (Ley №1448 2011). La Ley también reconoce como víctimas "al compañero o compañera permanente, parejas del mismo sexo y familiar en primer grado de consanguinidad, primero civil de la víctima directa, cuando a esta se le hubiere dado muerte o estuviere desaparecida" (Ley $\mathrm{N}^{\circ} 1448$ 2011). Y no considera a miembros de los grupos armados organizados al margen de la ley como víctimas "salvo en los casos en los que los niños, niñas o adolescentes hubieren sido desvinculados del grupo armado organizado al margen de la ley siendo menores de edad" (Ley Nº1448 2011).

En la submuestra, las mujeres afectadas por el conflicto son identificadas bajo las definiciones propuestas en la Ley y a diferencia del significado establecido 
en la norma, se incluye como víctimas a mujeres excombatientes menores o mayores de edad a las que se les produjo un daño generalmente relacionado con la violencia sexual.

En el análisis léxico se registra la palabra Víctimas con una frecuencia media. Derivaciones como Víctima, Victimario y Victimarios, presentaron muy baja frecuencia. Sin embargo, cuando se incluyó en los textos periodísticos la palabra Víctima en singular, se hizo alusión al nombre común víctimas que sostuvo además una relación directa con la palabra Mujeres. Desde este referente, se incluyen afectaciones que en general ocurrieron a las mujeres por el conflicto y se especifican violencias basadas en género que sucedieron en periodos anteriores al proceso de negociación de paz.

En el $21 \%$ de los casos la ocurrencia de la palabra Víctimas hizo referencia de manera concreta a mujeres y a la violencia sexual ejercida contra ellas en desarrollo del conflicto armado. En menor medida se presentó una asociación con otros tipos de violencia como el desplazamiento forzado o el secuestro, que también se incluyeron.

Al revisar la colocación de otras palabras asociadas como Violencia, se pudo establecer que, en más del $60 \%$ de los casos, se ubicó al lado de la palabra Sexual, y en algunas ocasiones se situó con Género (donde se pueden incluir poblaciones clasificadas en categorías LGBTI) y con Contra la mujer, encontrándose una significativa asociación con el género femenino.

Por su parte, otras palabras y sus formas en plural como Delito(s) y Crimen(es), aún con bajo registro de frecuencia, obtuvieron una relación estrecha con la violencia en contra de las mujeres -también se nombraron como Delitos de género-, y cuando se vincularon con la Violencia sexual en la mayoría de los casos fueron asociados con el aborto forzado como un tipo de esta violencia.

\section{Mujeres como víctimas civiles}

Revista Zona Franca- Centro de estudios interdisciplinario sobre las mujeres (CEIM)- Maestría poder y sociedad desde la problemática de género (MG), Rosario, Argentina. ISSN, 2545-6504 http://zonafranca.unr.edu.ar/index.php/ZonaFranca| Numero 26 (2018). 
A partir de la muestra y la atribución otorgada por los medios de comunicación se pudo establecer que el $13 \%$ de las mujeres consultadas como fuente de información fueron caracterizadas como víctimas, aunque de modos diversos en cuanto al tipo de afectación, el lugar del hecho victimizante y el victimario asociado, entre otros elementos. Su rol dentro de los textos periodísticos las puede convocar como representantes de grupos de personas afectadas directamente por el conflicto, mujeres públicas, líderes comunitarias, amas de casa, campesinas o comerciantes. Sin embargo, y según los resultados de la submuestra, pocas alcanzan el lugar más protagónico de la información y, en mayor proporción, se ubican más como co-protagonistas en el relato ofrecido por los medios y periodos analizados.

La mayoría de mujeres afectadas por el conflicto presentes tanto en la muestra como en la submuestra fueron civiles quienes en muchos casos comportaban una conexión familiar con combatientes, especialmente integrantes de las fuerzas militares que en el desarrollo de su trabajo fueron secuestrados y en muchos casos asesinados.

En general, los artículos y las fuentes oficiales enuncian a las mujeres como víctimas para referirse a la reparación que estas necesitan frente a los eventos en los que resultaron afectadas y, particularmente en la información sobre la inclusión del enfoque de género en los acuerdos de paz, ellas fueron nombradas además para promover su participación en el posacuerdo. Cuando fueron sujetos testimoniales, ingresaron en los contenidos para, de un lado, recordar los eventos en los que fueron afectadas por el conflicto, y de otro lado, para resaltar su capacidad de perdón y reconciliación. Sólo en dos piezas periodísticas las fuentes presentadas como víctimas criticaron asuntos alusivos al proceso de paz.

Las mujeres enunciadas como víctimas, frente a otro tipo de fuentes de información, se introdujeron con una mayor caracterización sobre su aspecto físico y personalidad. Fueron frecuentes para ello su asociación a la familia (pareja, hijos

Revista Zona Franca- Centro de estudios interdisciplinario sobre las mujeres (CEIM)- Maestría poder y sociedad desde la problemática de género (MG), Rosario, Argentina. ISSN, 2545-6504 http://zonafranca.unr.edu.ar/index.php/ZonaFranca| Numero 26 (2018). 
e hijas), y algunas características físicas y expresiones que incluyeron el dolor, el sufrimiento, el perdón y la reconciliación como parte de ellas. En los casos donde se abordó la violencia sexual en general y el aborto forzado como un tipo particular de esta violencia, se insistió en la exigencia de la justicia frente a estos hechos.

\section{La maternidad y las relaciones familiares como constante}

Las narraciones en las que aparecen las mujeres como víctimas ligadas a la maternidad o a sus lazos familiares fueron constantes y reiteradas. La mayoría de sus testimonios fueron por la pérdida de familiares, sobre todo hijos o esposos. Los únicos relatos elaborados frente a la violencia sexual -un tipo de violencia que afecta de manera diferencial y contundente a las mujeres- fueron entregados por mujeres excombatientes de las Farc-Ep, que se reportaron unos como violaciones o actos de acceso carnal violento y, otros, como coacción para la interrupción del embarazo. A continuación, algunos ejemplos:

- "A ambas se les entrecorta la voz cuando hablan de Julián, el padre y el hijo. Pero también hablan de perdón y de reconciliación" ${ }^{5}$

- “Iván Márquez' abrazó a cada una de las 17 viudas que dejó esta masacre para pedirles perdón por lo sucedido. También abrazó a las madres que perdieron a sus hijos"6

- "Para salvarse, no tuvo más remedio que renunciar a la vida que crecía en su vientre."7

Estas asociaciones privilegiadas y reiteradas a la maternidad pueden ser problemáticas cuando se propone a las mujeres como proclives a la paz por el hecho de ser madres, debido a que tienden a reforzar el rol tradicional de las

\footnotetext{
${ }^{5}$ Morales, C. (27 de septiembre de 2016). 'Hoy no sentí lo que antes sentía con los señores de las Farc'. El Tiempo, p.6

${ }_{7}^{6}$ Pareja, D. (1 de octubre de 2016). 'Las Farc nos pidieron perdón con sinceridad'. El Tiempo, p.2

7 Mata, N. (14 de diciembre de 2015). "El Enfermero" seguía la política de abortos de Farc. EI Colombiano, pp.2-3

Revista Zona Franca- Centro de estudios interdisciplinario sobre las mujeres (CEIM)- Maestría poder y sociedad desde la problemática de género (MG), Rosario, Argentina. ISSN, 2545-6504 http://zonafranca.unr.edu.ar/index.php/ZonaFrancal Numero 26 (2018). 
mujeres desde un sentido biológico como únicas cuidadoras de los otros, fortaleciendo estereotipos que pueden afectar su autonomía (Villellas 2010:22).

Las asociaciones preferentes e insistentes a la familia, y en especial a los esposos e hijos, reflejan en muchos casos que el protagonismo de las mujeres se sigue valorando por su relación con los varones, característico del modelo androcéntrico de la cultura occidentalizada que privilegia esa experiencia de ser humano, y en su ausencia, las mujeres se visibilizan o se promueven para hablar de ese hombre ausente (la mayoría de veces por la muerte).

Lo anterior no solo explica la cultura y el impacto diferencial que el conflicto violento y la construcción de paz tienen sobre las vidas y cuerpos de mujeres y hombres, y las maneras en cómo estas ideas tradicionales asociadas a la construcción social de los géneros se representan de manera hegemónica en los medios de comunicación, sino que expresan también la diversas formas de ser mujeres que en esos mismos contextos de guerra y construcción de paz, construyen "representaciones emancipadas" (Perera 2003:6) y difunden la fortaleza y resistencia de aquellas mujeres llamadas por Magallón (2012) como Coraje, haciendo alusión entre otras a:

grupos que pelean contra la impunidad, del tipo Madres de Plaza de Mayo, CONAVIGUA o Viudas de Guatemala, Madres del Salvador, Madres de soldados rusos, y tantas otras que buscan a sus familiares desaparecidos y se enfrentan a dictadores y mafias (Magallón, 2006). (p.24)

Para el caso de Colombia se podrían referenciar experiencias como la de las Madres de la Candelaria, las Madres de Soacha, Mujeres caminado por la verdad, o el caso emblemático de Fabiola Lalinde y su "operación siriri", sin embargo, en este análisis fueron más comunes y frecuentes las versiones tradicionales ligadas al ser esposas y cuidadoras, que les son más propias a los medios de comunicación consultados. Según Perera (2003) existen tres tipos de representaciones que se pueden distinguir como hegemónicas cuando "les es 
típico un alto grado de consenso entre los miembros del grupo"; emancipadas, cuando "emergen entre subgrupos específicos, portadores de nuevas formas de pensamiento social"; y polémicas, cuando surgen "entre grupos que atraviesan por situaciones de conflicto o controversia social respecto a hechos $\mathrm{u}$ objetos sociales relevantes y ante los cuales expresan formas de pensamiento divergentes" (p.6). En este caso, prevalecen las representaciones hegemónicas en las que se define a las mujeres víctimas en posiciones pasivas y son menos visibles aquellas representaciones resistentes o emancipadas de las mujeres afectadas por el conflicto que se han constituido en agentes políticos.

\section{Guerrilleras: entre la invisibilidad y la representación como víctimas}

En la submuestra, las palabras y formas derivadas que hacen alusión a las mujeres en la guerrilla de las Farc-Ep no lograron una frecuencia significativa. Lo que se puede destacar es que fueron precisamente las palabras menos escritas en los textos periodísticos, siendo ausente en la submuestra la palabra Guerrillera. Para referenciar a las mujeres que conforman el grupo específico de las Farc-Ep se utilizó la forma plural Guerrilleras, y para aludir al conglomerado de las Farc-Ep donde se incluyen mujeres y hombres se utilizó la palabra Combatientes. Sin embargo, aunque con poca recurrencia, otras palabras clave como Exguerrilleras, Desmovilizadas y Excombatientes fueron utilizadas para significar a las mujeres que estuvieron vinculadas a esta guerrilla en un tiempo anterior al proceso de acuerdos de paz.

La baja recurrencia en términos de nominación refleja que, en general, a las mujeres de las Farc-Ep no se les otorgó una voz en la construcción de la información sobre el proceso de paz. Las únicas dos mujeres pertenecientes a la organización guerrillera que lograron un poco de visibilidad en esta cobertura, y que particularmente en los textos periodísticos no se nombraron como guerrilleras, fueron "Victoria Sandino" y "Erika Montero", dos líderes farianas que participaron directamente en la Mesa de Conversaciones. Mientras, las guerrilleras que no se ubicaron en la primera línea de representación del grupo en ese escenario, fueron 
invisibles y, en el momento en el que se hizo referencia a alguna de ellas, fueron denominadas como víctimas de violencia sexual.

Principalmente la palabra Guerrilleras fue utilizada en la mitad de los casos en relación a la violencia ejercida contra las mujeres del grupo y con la imposibilidad de decisión sobre sus vidas y sus cuerpos. En la pieza periodística "“El Enfermero" seguía la política de abortos de Farc" ${ }^{3}$, se encuentran varios ejemplos. Para referirse a las mujeres de la guerrilla, se utilizaron palabras como "sometidas" o "presionadas", puesto que quedar embarazadas las podía llevar a perder la vida o por el peligro de la práctica del aborto en condiciones precarias o por ser "castigadas con el fusilamiento" en su elección por la maternidad.

El aborto se representó en esta y otras piezas periodísticas como "delito", "drama" o "política" de ejercicio de poder sobre el cuerpo de las mujeres, y sólo en una de las concordancias de la palabra Aborto se presentó como "derecho", "lucha" y "conquista" de las mujeres, especialmente de las Farc. La interrupción del embarazo se relaciona con "la maternidad libre como derecho humano fundamental [con lo cual se hace referencia a] un acto voluntario a partir de la decisión de la mujer, de su deseo o asentimiento para gestar o parir" (Londoño 1996:197). Cabe anotar que a diferencia de la anterior excepción, la exposición del aborto como política, delito y drama fue realizada por varones externos a las FarcEp y mujeres desvinculadas al grupo. Particularmente, las palabras Combatiente y sus formas ex y plural, obtuvieron una relación directa con la palabra Aborto.

Con la inclusión de las únicas dos mujeres que lograron visibilidad como delegadas de las Farc en el proceso de negociación, con la inexistencia de otro tipo de mujeres del grupo insurgente como fuente de información y con la presencia reiterada de mujeres exguerrilleras como víctimas -mencionadas en

8 Mata, N. (14 de diciembre de 2015). "El Enfermero" seguía la política de abortos de Farc. El Colombiano, pp.2-3

Revista Zona Franca- Centro de estudios interdisciplinario sobre las mujeres (CEIM)- Maestría poder y sociedad desde la problemática de género (MG), Rosario, Argentina. ISSN, 2545-6504 http://zonafranca.unr.edu.ar/index.php/ZonaFrancal Numero 26 (2018). 
este fragmento-, se puede plantear que la representación que se construye sobre las mujeres de la guerrilla, con contadas excepciones, es la de mujeres sin poder de decisión, vulneradas, y que, tal y como se propone con las mujeres afectadas en el conflicto, deben ser defendidas y reparadas incluso del grupo al cual pertenecieron alguna vez.

\section{Conclusiones}

El análisis de los periodos y medios de comunicación seleccionados en función de las representaciones de las mujeres durante la cobertura de los acuerdos de paz demuestran, a grandes rasgos, que estas siguen siendo infrarepresentadas y su lugar en la información continua desigual frente a los varones.

Cuando se presenta a las mujeres en los contenidos informativos son escasas las representaciones desde su diversidad, considerando que Colombia es un país pluriétnico y multicultural, la poca presencia o ausencia de mujeres afro 0 indígenas y la inexistencia de las mujeres ROM, pone de relieve su exclusión como actores sociales relevantes en la información publicada, reafirma estereotipos sobre la participación de estas comunidades en la sociedad y confirma que estos grupos están despojados de poder.

En términos del protagonismo colectivo, los temas que se refirieron exclusivamente a las mujeres y la paz tampoco alcanzan relevancia. En gran medida esta información fue aportada durante el periodo de análisis correspondiente a la presentación del enfoque de género en los acuerdos, lo que se puede considerar como una oportunidad perdida para la narración de otros aspectos alcanzados durante el proceso de negociación, y en el que las mujeres y la comunidad LGBTI participaron de manera activa y novedosa en lo que se refiere a los acuerdos de paz mundial.

En cuanto al protagonismo individual, aquellas mujeres identificadas como víctimas se propusieron en los textos periodísticos en la mayoría de los casos en lugares co-protagónicos, es decir, compartieron el lugar destacado de la estructura 
informativa en compañía de otras víctimas, o con los colectivos mujeres y víctimas. Particularmente, y aunque la violencia sexual fue el tema en el cual más se profundizó en las piezas periodísticas alusivas al enfoque de género en los acuerdos o en la intersección mujeres y paz, la presencia de mujeres afectadas en el contexto del conflicto como fuente de información en niveles protagónicos no se debe a la violencia sexual sino a narraciones en las que aparecen como víctimas en la categoría estipulada por la Ley 1448 como cónyuge, compañera permanente, y familiar en primer grado de consanguinidad. Es decir, el tema que visibiliza al colectivo mujeres es el de la violencia sexual, pero lo que las individualiza de manera destacada es la pérdida de sus hijos o esposos asesinados o desaparecidos en la guerra. Esta propuesta refleja el androcentrismo en el discurso informativo al destacar y valorar, en este caso, la palabra de las mujeres en conexión con los hombres de su familia (padre, esposo, hijo).

Por su parte, a las mujeres guerrilleras se les invisibilizó en la información con su voz propia; las pocas mujeres relacionadas al grupo, quienes también fueron enunciadas como exguerrilleras, desmovilizadas y excombatientes, fueron presentadas como víctimas y "sometidas" por su grupo, con lo que se puede construir la idea según la cual las mujeres de la guerrilla de las Farc-Ep estaban desprovistas de poder no sólo en el espacio formal de las negociaciones de paz, sino en su grupo y desde las decisiones sobre su propia vida y cuerpo.

En los medios de comunicación analizados no logran posicionarse las ciudadanas o los colectivos de la sociedad civil que comportan distintas formas de participación política y social, en otros términos, una participación referida a "transformar las relaciones de poder-poder, que devienen en subordinación para las mujeres" (Jaramillo, Montoya, Valencia 2008:29) una participación vinculada al ejercicio de la ciudadanía plena que no se agota con el voto o con la participación político electoral y que se vincula con acciones en favor de la paz o desde el pacifismo. 
Si la representación mediática posibilita "hacerse una idea" de un grupo, un momento o un acontecimiento social (Tablante 2005:163), la revisión de las representaciones que los medios de comunicación han co-producido, co-producen y reproducen de las mujeres en el marco del proceso de paz y del posacuerdo construyen las ideas que se tejen a diario de lo que significa ser mujer en Colombia, representaciones que se manifiestan tanto en las maneras del ser mujer que más frecuentan los medios, como en las más invisibilizadas.

A modo general, una de las representaciones más relevantes como "formas de pensamiento social" expuesta en los medios y periodos revisados, remite a las mujeres como víctimas, con frecuencia pasivas y en asociación exclusiva al rol tradicional de ser madres y esposas. Sin embargo, una indagación de las versiones que se co-producen de las mujeres desde los medios alternativos y nuevos medios, aportaría una comprensión más amplia sobre hasta dónde circulan tipos de representaciones hegemónicas, emancipadas o en disputa del ser mujeres en la sociedad colombiana en contextos de conflicto, posacuerdo y construcción de paz; en especial para reconocer lo que ellas significan, encontrar otras posibilidades de participación, y promover reflexiones que permitan generar conciencia y acción para el reconocimiento de la voz de las mujeres como ciudadanas que aportan a la construcción de paz, desde la narración cotidiana de los acontecimientos de carácter públicos.

\section{Bibliografía}

Acerdo general para la terminación del conflicto y la construcción de una paz estable y duradera (2012). Alto comisionado de paz. Recuperado de http://www.altocomisionadoparalapaz.gov.co/procesos-y-conversaciones/acuerdogeneral/Documentos\%20compartidos/Acuerdo General para la terminacion del conflicto.pdf

ALCINA, Miquel (1993). La construcción de la noticia. Paidós comunicación, Barcelona, p. 208.

Revista Zona Franca- Centro de estudios interdisciplinario sobre las mujeres (CEIM)- Maestría poder y sociedad desde la problemática de género (MG), Rosario, Argentina. ISSN, 2545-6504 http://zonafranca.unr.edu.ar/index.php/ZonaFranca| Numero 26 (2018). 
BRAH, Avtar (2014). "Diferencia, diversidad y diferenciación". Otras inapropiables. Feminismos desde las fronteras, Traficantes de Sueños; Madrid, 107-136.

BURKLE, Martha, \& REIGADA, Alicia (2006). "Teoría crítica feminista y comunicación". Redes.com Revista de estudios para el desarrollo social de la Comunicación, №3, 11-21. Recuperado de http://revistaredes.hospedagemdesites.ws/index.php/revista-redes/article/view/74

CASTRILLÓN, Gloria. (2015). “¿Víctimas o victimarias? El rol de las mujeres en las FARC. Una aproximación desde la teoría de género". Opera, №16, 77-95. Recuperado de https://revistas.uexternado.edu.co/index.php/opera/article/view/4142

FAIRCLOUGH, Norman. (1995). Critical Discourse Analysis, Longman, London and New York, p.265

HORTA, Julio. (2013). "Representaciones mediáticas. Tres notas sobre los procesos semióticos en los medios masivos". Comunicación y Medios, №28, 96 112. doi:10.5354/0719-1529.2014.27085

JARAMILLO, Ángela, MONTOYA, Martha \&VALENCIA, Mónica. (2008). La política y lo politico: la palabra y la voz de las mujeres. Corporación Vamos Mujer, Medellín, p.55

JODELET, Denise. (1986). "La representación social: fenómenos, concepto y teoría". Psicología Social, Vol.2. Pensamiento y vida social. Psicología social y problemas sociales, Paidós Barcelona, 469-495.

Ley 1448 (Victimas y restitución de tierras). Ministerio del Interior. República de Colombia. Junio 10 de 2011.

LONDOÑO, Luz María. \& NIETO, Yohana. (2006). Mujeres no contadas. Procesos de desmovilización y retorno a la vida civil de mujeres excombatientes en Colombia 1990 - 2003. La Carreta editores, Medellín, p.293

LONDOÑO, María Ladi. (1996). Derechos sexuales y reproductivos. Los más humanos de todos los derechos. ISEDER, Cali, p.334 
LUNA, Lola, \& Villarreal, Norma. (2011). Movimientos de Mujeres y participación política. Colombia del siglo XX al siglo XXI, Gente Nueva, Bogotá, p.229

MAGALLÓN, Carmen. (2012). "Representaciones, roles, y resistencias, de las mujeres en contextos de violencia", Revista Crítica de Ciências Sociais, N96, 9-29. doi: $10.4000 /$ rccs. 4797

MESA, Manuela. (2010). "Mujer, paz y seguridad: la Resolución 1325 en su décimo aniversario". Balance de una década de paz y conflictos: tensiones y retos en el sistema internacional: anuario 2010-2011, Fundación Cultura de Paz, Barcelona, 43-64.

MONTERO, Dolores. (1997). "Conflicto y medios de comunicación en la construcción del conflicto social". Mujer, violencia y medios de comunicación, Secretariado de Publicaciones, Universidad de León, (pp.163-172).

MOSCOVICl, Serge. (1979). El psicoanálisis, su imagen y su público. Huemul S.A., Buenos Aires, p.363

NAVARRO, Luis. (2008). "Aproximación a la comunicación social desde el paradigma crítico: Una mirada a la comunicación afirmadora de la diferencia", Investigación y desarrollo (Barranquilla), Vol.16, №2, 326-345. Recuperado de http://www.redalyc.org/articulo.oa?id=26816207

PERERA, Maricela. (2003). "A propósito de las representaciones sociales: apuntes teóricos, trayectoria y actualidad". CIPS, La Habana, Cuba, (pp.1-35). Recuperado de http://biblioteca.clacso.org.ar/Cuba/cips/20130628110808/Perera perez repr soci ales.pdf

Registro Único de Víctimas, RUV. (01 de mayo de 2018). Red Nacional de Información Unidad de Víctimas. Recuperado de https://rni.unidadvictimas.gov.co/RUV

SÁNCHEZ GÓMEZ, Olga. CARRILLO, Abelardo. BABATIVA, Jose. RENGIFO, María del Pilar. \& SILVA, Liliana. (2017). Encuesta de prevalencia de violencia sexual en contra de las mujeres en el contexto del conflicto armado colombiano (2010-2015). Campaña Violaciones y otras violencias: Saquen mi 
cuerpo de la guerra, Bogotá, p.39 Recuperado de http://humanidadvigente.net/wpcontent/uploads/2017/08/Encuesta-de-prevalencia-de-violencia-sexual-CSCG.pdf

SÁNCHEZ LEYVA, María José. (2007). Crítica feminista y comunicación. Comunicación Social Ediciones y Publicaciones, Sevilla, p.272

SÁNCHEZ MORA, Mayra, \& RODRÍGUEZ, Zuriñe. (2015). "Acciones colectivas de las organizaciones de mujeres por la paz en Colombia". Revista Paz y Conflictos, Vol.8, №2, 149-177. Recuperado de http://revistaseug.ugr.es/index.php/revpaz/article/view/3190

SAU, Victoria. (2000). Diccionario ideológico feminista. Vol. I. Icaria, Barcelona, p.321

TABLANTE, Leopoldo. (2005). "Representaciones sociales, medios y representaciones mediáticas". Temas de Comunicación, №12, 117-167. Recuperado de http://revistasenlinea.saber.ucab.edu.ve/temas/index.php/temas/article/view/256

TAMAYO, Alba. (2013). "Movimientos sociales de mujeres en el conflicto armado colombiano: política participativa y periodismo. Reflexiones en torno al caso de las Madres de la Candelaria", Comunicación y Medios, №28, 80-95. doi: 10.5354/0719-1529.2013.27161

TAMAYO, Camilo, \& BONILLA Jorge. (2014). "El deber de la memoria. La agenda investigativa sobre la cobertura informativa del conflicto armado en Colombia, 2002-2012", Palabra Clave, Vol.17, № 1, 13-45).

VAN DIJK, Teun. (1990). La noticia como discurso. Comprensión, escritura y producción de la información. Paidós, Barcelona, p.284

VILLELLAS, María. (2010). "La participación de las mujeres en los procesos de paz. Las otras mesas". ICIP Working Papers N05. Recuperado de http://icip.gencat.cat/web/.content/continguts/publicacions/workingpapers/arxius/wp 105 cast.pdf 